\title{
Vanguardias silenciadas: tejidos de la memoria
}

\author{
Marisol Vera / Olga Grau
}

\section{Rosario Orrego ${ }^{1}$}

“Nos duele confesarlo, pero la verdad es que las mujeres (salvo honrosas excepciones) son las grandes sacerdotisas del abominable culto tributado al becerro de oro! Ellas son las que por satisfacer su sed de lujo impelen a sus maridos y hacen comprender a sus novios la necesidad de ganar mucho dinero. Si los hombres hacen las leyes, las mujeres hacen las costumbres: sobre ellas cae la mayor responsabilidad de todo lo que tiene de materialista, de interesado y de penoso para toda alma noble las costumbres del siglo."

“Dicen las mujeres que los hombres del día pretenden hacer un negocio del matrimonio, y que al informarse de una señorita no preguntan si es virtuosa, si es bien educada, sino si es rica... Mas, hablando entre nos, ¿pueden hacer otra cosa? ¿Cómo, dirán ellos, acertar con aquella mujer que se contente con lo que Dios y mi trabajo me den, sin pedirme otra cosa que mi cariño?

Si esto no es cierto, tengan las señoras la bondad de perdonarnos, que sólo el más sincero interés por su bien ha guiado nuestra pluma." 2

\section{Rosa Rubí}

“¿Qué es la obrera?

La obrera es una máquina de carne, cuyo sistema reproductor, ha sido transformado en productor. La obrera, o sea el caballohembra, desempeña -haciéndosela un honor- dos importantes papeles. Es artefacto sexo-sensual y es bestia de carga o máquina industrial. Ella debe, durante el día trabajar, en el taller o prisión, servir como una esclava y arrastrarse como un reptil, para ganar su alimento miserable, el de sus hijos y parte del de su marido o amo. En la noche asear su casa, lavar la ropa, hacer de comer, acariciar a sus niños, y servir de madre, de hija, de esposa y de 
animal tolerante y satisfaciente del hombre-perro que ladra, que come, que muerde, que empuerca y halaga, miserablemente -sin que nunca venga un rayo de luz, una nota dulce, una sonrisa, una esperanza, a tocar sonoramente sus delicadas fibras del corazón de la mujer que sufre y que siente.

La obrera debe sonreír fingidamente al patrón, debe oírle sus impertinencias y estupideces, debe humillarse, servilmente, a la torpe y orgullosa patrona, debe trabajar mucho, el doble que un hombre, para ganar la tercera parte de lo que por el mismo tiempo o trabajo gana éste, debe ser muy obediente y generosa, $\mathrm{y}$, por fin, debe serle al esposo, más fiel que las burguesas beatas a sus confesores. ¿Quieres saber mejor, qué es la obrera? Pues bien, mas tarde os lo diré con más franqueza o amplitud." 3

\section{Teresa Claramunt ${ }^{4}$}

“Yo dejé de ser católica, no por las pillerías de algunos curas o gente católica, sino porque al tener uso de razón comprendí que el catolicismo católico era muy inferior a mi moral y a mis aspiraciones y aunque todos los católicos fueran buenos yo sería atea. Soy anarquista porque no podría ser otra cosa mientras mi organismo funcione con la regularidad que ha funcionado hasta hoy. Siento amor sin límites, y la infame sociedad actual pone en mi noble deseo una valla. Anhelo el goce, y solo dolor me rodea. Deseo la vida, y la muerte con su faz fría se presenta a mi vista. Lo bello, lo grande, me fascina, y por doquier veo fealdades, pequeñeces y miseria. Amo el trabajo por ser fuente de vida, y a los que trabajamos nos roe la anemia, las escaceses nos agobian, el hospital es nuestra recompensa. Creo posible una sociedad más justa, más bella, más humana, que hemos dado por llamar la sociedad anarquista, ácrata o libertaria; y aunque todos los hombres que se titulan anarquistas cometieran mil crímenes a diario, continuaría yo llamándome tal con noble orgullo, aún ante un tribunal a la Marzo, muriendo convencida de la pureza del ideal, convencida a la vez que los crímenes perpretados son resultados de la sociedad actual, porque todos somos hijos del ambiente que nos rodea, y en una sociedad tan corrupta, todo crimen tiene clara explicación y hasta su justificación." ${ }^{5}$ 
“La guerra es una calamidad social condenada por todos los hombres de sentimientos humanitarios.

La ciencia y la filosofía han demostrado hasta la evidencia que la guerra y sus resultados son consecuencia de la perversión moral de individuos ambiciosos que sólo desean la satisfacción de sus pasiones y vicios a costa del dolor ajeno.

A fin de poner término a esta calamidad social que nos invade -la guerra- preciso es que todos los hombres conscientes inicien una tenaz campaña contra la institución militar, causante de muchos dolores humanos y sostén de la tiranía social imperante.

Disuélvanse los ejércitos que son agrupaciones dañinas e improductivas y habremos contribuido así a la desaparición de las patrias, borrando fronteras, para encontrar bajo los pliegues de la hermosa fraternidad el anhelado amor mundial que desean los que luchan por los modernos principios de justicia y verdad. ¡Muera pues el canibalismo militar!”6

\section{Adriana Palomera y Alejandra Pinto sobre textos de mujeres aparecidos en la prensa anarquista en Chile (1897-1931):}

“No es menos cierto que la visibilización de las voces de estas mujeres, se enmarcan dentro de la emergencia de un 'sujeto colectivo', donde tuvo predominancia el concepto de 'clase', no obstante, creemos que esta mirada femenina enfatiza la experiencia 'interior', la reelaboración particular que realiza un sujeto de su experiencia, vivencia y condición. De este modo las mujeres que exponen sus ideas y pensamientos no representaban sólo el pensar una clase o de un género, sino que hablaban desde su particular condición de marginadas y libertarias.

Estos textos, demuestran claramente que las mujeres no quedaban excluidas de la posibilidad de generar discurso, logrando que a pesar del predominio de los hombres en el plano de la escritura ideológica, ellas fueran capaces de convertirse en sujetos históricos, objetivando su condición para hablar, aún desde la exclusión, de nuevas posibilidades para ellas como partícipes de un proceso global. 
Desde nuestra mirada contemporánea, las mujeres que escribían en la prensa anarquista comparten el contexto que vio nacer al movimiento feminista. Pero, su voz no se alzó sólo para reivindicar un 'espacio más amplio para la mujer'; sus acciones y letras no estaban orientadas en un sentido de querer más poder para las mujeres. Como anarquistas estaban en contra del poder, en todas sus expresiones, especialmente en aquellas que hacían que la sociedad se dividiera en clases sociales, en las que unos eran los poseedores y otros los que no contaban más que con la fuerza laboral.

La emergencia de este cruce entre la anarquía y las mujeres, es un 'espacio' que permitió que ellas personificaran esta idea de una peculiar manera, donde la sensibilidad y mirada temática, eran enfocadas no sólo desde el plano teorizante, sino también desde una experiencia cotidiana que interpelaba y denunciaba concretamente a las mujeres." 7

\section{Carmela Jeria ${ }^{8}$}

“El ideal que en estos momentos está preocupando a una parte de nuestro sexo, merece no solo nuestra atención sino también la de toda persona amante de la igualdad y adelanto de los pueblos.

Ese ideal, la emancipación e instrucción de la mujer, ha sido en éstos últimos tiempos muy debatido.

Muchos defensores ha encontrado; muchos han roto lanzas en pro de la emancipación de la mujer obrera.

Pero... ¡triste es decirlo! No se han dado pruebas de verdadera sinceridad. Con dolorosa sorpresa nos hemos impuesto muchas veces, del comportamiento que observan en el hogar algunos valientes partidaristas del feminismo que, públicamente, protestan del yugo ignominioso que sobre nuestras cabezas pesa y que en diarios y periódicos piden una y mil libertades para su sumisa compañera de infortunio.

Con el alma acongojada por el más cruel escepticismo, que nos hace dudar de todo, hemos penetrado en el hogar de uno de esos partidarios de la mujer: La amante esposa, cariñosa y humilde, implora mudamente con tiernas miradas un poco de compasión o amor de su indiferente compañero; un poco de libertad e 
instrucción que le permita desempeñar su papel de madre con más capacidad.

Pero nada... el propagandista incansable del adelanto de la mujer es sordo a los ruegos de su esposa (...) frases amargas e hirientes que recuerdan su mísera condición de esclava.

No ejerce, pues, la mujer en el hogar derecho alguno (...) Tócanos a nosotras mismas, si no nos acompañan con la debida sinceridad, procurarnos nuestro bienestar, para lo cual nos debemos desde luego poner en pié, con decisión y valentía, y parafraseando a un notable pensador socialista, digamos: "nuestra emancipación verdadera está en nosotras, debe ser obra de la mujer misma." ${ }^{9}$

\section{Martina Barros ${ }^{10}$}

“En efecto, ¿qué es lo que él (John Stuart Mill) quiere con este libro? Restablecer la naturaleza, volver a colocar la sociedad en su punto de partida, reunir los hombres en el rústico hogar de los tiempos primitivos alrededor del fuego que prepara para su cuerpo los alimentos groseros y hace nacer en los corazones los primeros afectos delicados. Examinar ese momento en que la sociedad se organiza, sorprender el abuso de la fuerza, el origen de las preocupaciones y las desgracias de la humanidad. Y enseguida trasportar ese estado social a nuestra época despojándolo de toda su barbarie y conservándole toda su libertad. He aquí el propósito de este libro. Es un trabajo de demolición y de reconstrucción: derriba la sociedad. Y para esto ¿qué debemos hacer? Darle a la mujer la misma libertad que tiene el hombre para emplear sus facultades en el sentido que mejor le cuadre, es decir darle la libertad de instrucción y la libertad para hacer uso de sus conocimientos. Stuart Mill exponiendo las ventajas que reportaría la sociedad de la educación igual del hombre y de la mujer, se detiene a hacer ver el considerable aumento en el número de las personas aptas para desempeñar las ocupaciones que hoy se acuerdan sólo al hombre; el estímulo que recibiría éste viéndose en la necesidad de justificar esa superioridad que pretende sobre la mujer; y siendo ésta más instruida sería también más provechosa la influencia que ejerce sobre el hombre como madre, y como esposa. Pero del cultivo intelectual 
resultaría todavía ventajas de un orden superior. Aceptando la diferencia moral que Buckle establece se acepta también que educar a la mujer no es simplemente aumentar el número de los seres útiles a la humanidad, es también utilizar facultades que el hombre espontáneamente no posee y que sin embargo son de un alcance incalculable en el dominio de las ciencias. (...) Educar a la mujer es desarrollar esas facultades en el terreno que más fácilmente y con mejores resultados deben desarrollarse desde que en ella se producen espontáneamente."11

\section{Alejandra Castillo a propósito del Prólogo de Martina Barros:}

“(...) será, precisamente, el concepto de 'libertad' lo que se revele en la traducción de Martina Barros. Estar libre 'de impedimentos' y ser libre para 'buscar el propio camino' son los elementos que Barros rescatará del texto de Mill. En este punto, Martina Barros señalará que 'la libertad es la única solución de ese problema social'. Que la mujer sea libre para seguir el camino por donde la guían los instintos de su corazón y las aspiraciones de su espíritu. Así sólo será madre la que se sienta con las aptitudes que exige la misión más elevada y el sacerdocio más santo que pueda concebir la imaginación sobre la tierra (...) darle a la mujer la misma libertad que tiene el hombre para emplear sus facultades de instrucción y libertad para hacer uso de sus conocimientos.

Ser libres para decidir autónomamente sobre la propia vida. Ser libres, también, para acceder a una educación que permita el desarrollo de las múltiples potencialidades del individuo. Dicho de otro modo, se exige un espacio de libertad y de decisión que permitirá, paulatinamente, generar las condiciones necesarias para pedir por la igualdad. Tránsito que será avizorado por Martina Barros, en su prólogo en la medida que constata, no sin pesar, "(...) que en nuestro siglo en que se han llegado a borrar las diferencias de señor y esclavo, en que se han hecho desaparecer las odiosas distinciones de razas y colores, todavía sea temerario, imprudente y hasta peligroso pedir que se borre la triste diferencia en mala hora establecida entre el hombre y la mujer, esa odiosa distinción de los sexos. Nacida esa distinción de los sexos a la sombra de la fuerza, se ha sostenido merced a una educación 
viciosa que hace al hombre mirarse desde la cuna como un ser superior a la mujer".

He aquí nuevamente, la huella de la aporía, la fluctuación entre la libertad y la igualdad, marcas de una aporía irreductible. Marcas de un conflicto no resuelto entre dos de las palabras maestras del derrotero político y filosófico de Mill: libertad e igualdad. Señas de un decir ambiguo que harán posibles tanto discursos de individuación como también discursos de emancipación política. Será precisamente esta aporía - la tensión de este entre dosla que permitirá que el discurso feminista de comienzos de siglo fluctúe entre la demanda de sólo los derechos civiles hasta la petición de los derechos políticos. Aporía que, más que paralizar al discurso feminista entre dos posiciones antagónicas, permitirá el desarrollo de diversas hablas feministas. Sólo teniendo en cuenta esta aporía -la aporía con la que se inaugura el decir feminista chileno- será posible entender el por qué discursos feministas antagónicos -orientados o bien a la derecha o bien a la izquierda del espectro político nacional- reivindicarán a Martina Barros a la hora de pesquisar las primeras huellas del feminismo en Chile."12

\section{Ernestina Pérez ${ }^{13}$}

“¿Por qué nos hacemos alcohólicos? $1^{\circ}$ Porque las bebidas provocan una sensación ficticia agradable, dan una impresión también ficticia de fuerza y facilidad para el trabajo, con la depresión consiguiente. $2^{\circ}$ La tentación y la imitación (sobre todo este gran factor común, del mayor número de las acciones humanas). $3^{\circ}$ La falta de hogar. En lo obreros de las pampas salitreras y zonas mineras que viven en pueblos y aldeas compuestas casi solamente de cantinas y prostíbulos que se mantienen exclusivamente de la venta de bebidas alcohólicas... ¿Qué debemos hacer para evitar el alcoholismo?... Que las sociedades de temperancia, las ligas antialcohólicas se aumenten y sus miembros imiten al apóstol chileno.... Dar conferencias y publicar artículos antialcohólicos en todas partes. Distraer a las clases obreras con espectáculos morales gratis o muy baratos. Con ejercicios físicos al aire libre. Baños gratis sobre todo en los días de fiesta. Aumentar todos los deportes, tiro al blanco en adultos y niños, estimulándolos con premios.... 
Como decía al principio todos tenemos la obligación de contribuir a esta caritativa, patriótica y humanitaria campaña y pedir que se apruebe el proyecto de Represión del Alcoholismo y enfermedades de trascendencia social...."14

\section{Gabriela Mistral ${ }^{15}$}

"La libertad de enseñanza debería ser, en el lote de libertades, defendida apasionadamente por cada hombre que es verdaderamente un liberal: cuando se niega derecho a una sociedad radical para mantener una escuela, como cuando se lo niega a una institución católica, debería levantarse la misma protesta, porque las corporaciones más extremas existen sobre un cimiento delicadísimo: el de la tolerancia; cuando éste se debilita, el oído fino escucha la crujidura del suelo entero. ( ) Yo estimo que la misión urgente que corresponde a la escuela católica en esta hora, es la unión de las clases sociales. Ha solido dividirlas con la tendencia aristocrática que ha adoptado a veces, educando aparte al hijo del obrero del hijo del empleado, o al hijo del empleado del hijo del rico. ( ) Pero cuando en la América se anotan errores o defectos de tal o cual grupo católico, suele caerse en la ligereza de escribir Iglesia donde debe decirse un nombre de caudillo o uno de corporación."16

"Y, es que a medida que la luz se hace en las inteligencias, se va comprendiendo su misión y su valor y hoy ya no es la esclava de ayer sino la compañera, la igual. Para su humillación primitiva, ha conquistado ya lo bastante, pero aún le queda mucho que explorar para entonar un canto de victoria." ${ }^{\prime 17}$

\section{Raquel Olea interpretando a Gabriela Mistral:}

“¿Fue feminista Gabriela Mistral? ¿Es feminista su poesía, su escritura? Las preguntas han sido difíciles de dilucidar y las posiciones críticas, una vez más, intentan resolver totalizadoramente la respuesta. Establecer una pregunta por la relación de Gabriela Mistral con el feminismo interroga la relación de la poeta con el pensamiento y el activismo social, en una época 
de efervescencia y cambio políticos, pero también interroga su propia relación con el nombrar(se) y asumir un lugar estable de pertenencia relacionado con posiciones políticas, en este caso respecto de las políticas feministas de su tiempo. Desde su perspectiva de la adhesión a la lucha sufragista, Gabriela Mistral no se reconoció feminista, tampoco sufragista, sus escritos enuncian más dudas y conflictos

Que adhesión al movimiento. Pero su posición no está libre de ambigüedades y contradicciones -enunciadas en sus textosque la sitúan de manera ambivalente entre la comprensión del feminismo como una necesidad y la desconfianza en sus efectos emancipadores para la vida de las mujeres, particularmente en lo relativo a un efecto alterador de la maternidad que ella considera lo "propiamente femenino".

Gabriela Mistral es una de las primeras escritoras latinoamericanas que escribe desde una conciencia que registra la discriminación y la desigualdad que padecen las mujeres, sus escritos producen un posicionamiento de sujeto social femenino en la escritura. Una parte importante de su prosa está traspasada de reflexiones relacionadas con la subjetividad y la vida de las mujeres, con sus condicionamientos íntimos, sociales y culturales, con las formas de vida exigidas socialmente; con las respuestas y las resistencias a las demandas y mandatos a la feminidad: la maternidad, el deseo, las condiciones de trabajo, el destino de lo femenino, los discursos amorosos y las experiencias de la vida campesina y popular, fueron objeto recurrente de su preocupación, en una búsqueda de justicia."

“Desde sus primeros escritos referidos a la condición de las mujeres, la poeta se sitúa en el discurso moderno de la igualdad de los sujetos y el desarrollo del progreso humano como utopía social. En "La instrucción de la mujer", artículo publicado en el diario local La Voz del Elqui (1906), hace una analogía entre el desarrollo de la mujer y el desarrollo del progreso humano, reflexiona sobre la ausencia de las mujeres en el pensamiento humanista y científico, enunciando su posición moderna: "hagámosles amar las ciencias más que las joyas y las sedas". Asimismo, el deseo de emancipación la hace rechazar el destino femenino situado sólo en la familia: "Es preciso que la mujer deje de ser la mendiga de protección; y pueda vivir sin que tenga que sacrificar su felicidad con uno de esos repugnantes matrimonio modernos". 
Las palabras de Mistral la instalan con precisión en el pensamiento ilustrado moderno, que aboga por la igualdad económica y la emancipación de las mujeres. Su adhesión a los principios democráticos de igualdad y libertad para todos los sujetos sociales, podrían acercarla al feminismo liberal de la época. Sin embargo, prefiere mantenerse fuera de adhesión ideológica. En 1948 en "Recado para un congreso de mujeres en Guatemala", escribe: 'yo pido a ustedes, con un fervor de ausente que quiso hacer presencia, la gracia de que recojan la ofensa que llega a parecer befa, hecha al trabajo de nuestro mujerío rural. La reforma que el feminismo debe clamar como la primera, es la igualdad de los salarios, desde la urbe hasta el último escondrijo cordillerano'."

“Como Antígona, Mistral entierra el amor familiar y el vínculo consanguíneo para deambular por la incertidumbre y lo infamiliar, para errar, en soledad, por el desvarío de los signos, para constituirse en sujeto de otra experiencia. El gesto produce paralelamente su apartamiento, su desplazamiento de la ley que encauza la palabra femenina hacia lo (aún) incognoscible.

La poética de la madre que construye la escritura mistraliana, su poetizar la madre, su poema de la madre -diría Marchantreúne la pluralidad significante que astilla la unidad del signo. Mistral escribió la eternidad como dato genérico ineludible, como perentoriedad de la existencia femenina, pero la apertura del significante ejercida en su escritura produce su multiplicidad. Del mismo modo y con la misma intensidad con que escribió la identificación femenina en la madre, la poeta escribió su denegación, en versos que desplazan la identidad de la sujeto hacia otros derroteros, entre ellos, como se señaló, la escritura como constitución de sujeto. La maternidad como representación de una identificación denegada, en su discurso, es sustituida por la opción de una soledad productiva, la de la escritura. Mistral no asume ni nombra la escritura como forma de maternidad, como ha leído alguna crítica, creo más bien que ella opera un radical desplazamiento de la maternidad hacia el destino de soledad y locura, significado en el hallazgo y don que desplaza la maternidad; no hay ampliación de la función materna, en la escritura, sino desplazamiento de un goce."18 


\section{Eliana Ortega leyendo a Mistral}

“Leer a Mistral hoy exige forzar el ojo, mirar de frente y de soslayo para desvincularnos de la matriarca, hecha a imagen y semejanza del Padre, matriarca erigida por el patriarca, y centrarnos en la madre-mujer, poeta-madre, amada-amante.

La amada-amante de Mistral es pues, la Otra original, indispensable comienzo con la que toda mujer establece su primera relación amorosa y su primera identidad, la Madre. Pero, la amada-amante de Mistral es también la contra-cara de la amante infeliz y despechada de las hablantes de Desolación, que son mujeres dependientes del hombre, despechadas por él, silenciadas y utilizadas por él. Situada en dichos desdobles contradictorios, la amada-amante se corporiza en la voz y la imagen de una mujer autodefinida tal como son sus "Locas mujeres". Así, la amadaamante es Eva/ Ave en una; es carne y espíritu, y es madre-mujer, lo que implica tanto tener una sexualidad activa como una espiritualidad potente. La amada-amante es, por ejemplo, la madre que con su fuerza cósmica definirá el futuro de la raza ya que "sus rodillas mecen la raza latina y no hay destino más grande y tremendo que el 'suyo' a esta hora".

La amada-amante suplanta a la amada sufriente en Desolación, que la crítica tradicional ha venido leyendo e imponiendo como estereotipada representación de la mujer y la maternidad en su lectura de la obra mistraliana. No hay duda que esta crítica se empeñó también en leer a Gabriela Mistral basándose en experiencias de su vida, también parciales. Si nos quedáramos con esa lectura parcial exclusivamente, veríamos a Gabriela Mistral anclada en una edad muy temprana, en un amor trágico y eterno, en otros platónicos y heterosexuales; en fin, la veríamos constreñida en una sexualidad bastante patológica. Conviene en este momento aventurarnos por el camino de la madre, nosotras también, y preguntarnos desde ese lugar el por qué se ha leído negando la complejidad de su ser mujer; ¿por qué se han silenciado sus largas, profundas e íntimas relaciones con mujeres que fueron personas centrales en su vida, y que por serlo, fueron conformando su identidad femenina como también su palabra mujer?

Ahora bien, tal como el patriarcado ha logrado separarnos de las madres, es decir, separarnos a las mujeres, silenciando o desvalorando la relación primordial, mare-hija, así también se silencian la multiplicidad de otras formas de relaciones entre mujeres. 
¿Hasta dónde lleva Mistral ese sentido de amor entre mujeres? ¿Cómo leer sus experiencias y deseos sexuales profundamente femeninos, si el patriarcado silencia toda experiencia sexual que no sea heterosexual, incluyendo las relaciones amorosas entre mujeres? ¿Cómo leer la experiencia amorosa, desdoblada de la experiencia de la maternidad para enmascarar un lesbianismo primigenio? Estas reflexiones, preguntas retóricas, nos ayudan a explicar el daño que se le ha hecho a Mistral al silenciar parte de su existencia vital: su sexualidad. Este silencio en relación a la vida de Gabriela Mistral nos ha deformado su imagen, y ha censurado la lectura de sus textos; por ejemplo, nos ha impedido reconocer la vitalidad, la sensualidad y su erotismo femenino y su voluntad; como también nos ha impedido captar en toda su profundidad la autotraición, el autoexilio y el dolor que van implícitos en la negación de una parte vital de su existencia. Es por eso que las lectura patriarcales se concentran en la represión de lo femenil mistraliano y en la sublimación de la sexualidad en la maternidad concebida según el patriarcado."19

\section{Amanda Labarca ${ }^{20}$}

“Con perdón de mis oyentes y amigos, me permitiré ahora enunciar sumariamente mi proposición: para conocer y alterar la condición de la mujer han influido en el pasado transformaciones sociales y económicas de gran envergadura, muy semejantes a las que hoy vivimos. Los cambios socio-económicos y tecnológicos son los que le deparan el substratum, la base de las transformaciones en la condición femenina.

Tanto hombre como mujer no actúan solos. Están inmersos en un conjunto social compuesto de infinitos círculos concéntricos que van desde la familia bipersonal hasta la humanidad. $Y$ tal como para examinar la situación del varón, hay que detenerse en la clase de actividad que se le exige, asimismo el recto análisis de la condición femenina no puede separarse de ese núcleo formidable que es la familia, entendiendo por ésta a la que permite la convivencia de varón, mujer e hijo. Extraer a la niña o a la cónyuge de este conglomerado, estudiándolas como si tuvieran existencia aislada, es principiar por reducir el horizonte del problema, pecado en que han caído más de un sociólogo y muchísimas feministas." 
“Llegamos así, a nuestra última proposición: carece de suficiente base biológica e histórica la hipótesis de superioridad o de inferioridad aplicables al hombre o a la mujer. Su función ante la especie, ante la supervivencia de ésta, ante la capacidad de progreso y de evolución, no disminuye ni se agranda en sus manos. Lo que la historia nos enseña es que en todas las edades, sean la de los siglos cavernarios como en esos contemporáneos que sufrimos y gozamos, han aparecido mujeres altamente dotadas, calificadas de tan valiosas como sus compañeros. Son egregias, son señeras, pero no han sido capaces -como tampoco el hombre-de crear una nueva variación en el género homo sapiens."

"Pero, ¿cómo enseñar si nosotras mismas -las mujeres- estamos bajo el peso de una supuesta inferioridad? A muchas les angustia la ausencia de plenitud en sus vidas. Es que generalmente no halla expresión la porción más valiosa de sus espíritus; el deseo de saber y comprender, la búsqueda de la bondad y la sabiduría." ${ }^{21}$

"La educación en boga obedecía a las normas patriarcales. Para que desempeñara su papel sumisa, graciosa, cumplidamente, no era menester otra enseñanza que la del catecismo, las labores domésticas, unos rudimentos del A B C y... todas esas artes frívolas y encantadoras de gustar (...) Después de porfiado empeño, unos tras otros, los liceos y las universidades comenzaron a abrir sus aulas al sexo tenido por inepto."

"Las adalides del movimiento hubieron de comprender, no obstante, que les sería imposible modificar los códigos, mientras no lo exigieran de una tribuna legislativa. Desde entonces, el feminismo adquiere proyecciones políticas y abarca todas las clases sociales."

Sobre la realidad de las mujeres ricas en los países desarrollados, dice: “...Las que se creen sin necesidad de trabajar, aquellas cuyas mentes no les alcanzan para darse cuenta de los problemas sociales, ni gustan de ninguna disciplina artística, ni palpitan con la cálida simpatía humana que requieren las obras filantrópicas, ¿qué hacen de sus energías? ¡Recuérdese que hace una generación apenas, esas mujeres eran capaces de dar a luz a 20 hijos! Ante el inevitable vacío de sus horas se frivolizan a conciencia (...) La vida carece para ellas de un objetivo intenso. Mientras la infeliz obrera se encorva en el trabajo, el hastío de la mujer rica adquiere caracteres patológicos." 
Sobre la realidad de las mujeres de América Latina: “La sociedad exige... y ordena a las mujeres: 'Sé alegre, sana y optimista para que sobrelleves sin desmayo tu fardo de eternidad y transmitas esos caracteres a tus hijos; dedícate al hogar y al cuidado de los tuyos y no te habitúes a las faenas que no son de tu órbita' (...) Y la mujer confiesa: 'Yo me casaría de mil amores, y que solícita madre sería, más, aunque me han cortejado, ninguno todavía me solicita en matrimonio...' ¿Qué hacer, entre los imperativos del sistema capitalista e industrial, y los naturales y muchísimos más necesarios impulsos de la raza?¿Cómo resolver esta antinomia mortal?"

"Así como parece de toda justicia y conveniencia el sufragio político femenino, podría dudarse de su oportunidad si sus adeptas no se preparasen para ejercerlo. Esto es muchísimo más urgente que la dictación de la ley (...) La ley que les conceda derechos civiles y políticos vendrá en estos países hoy, mañana o pasado. Pero hay que esperarla con la lámpara del espíritu encendida. No correr el riesgo de que los acontecimientos nos sobrecojan, sino preverlos con inteligencia, participando desde luego en los asuntos públicos." 22

"Se condena la posibilidad de que una ley permita el divorcio, y se cierra los ojos ante el hecho de que a diario se están fallando anulaciones matrimoniales en todas las cortes de Chile! Es decir, que la clase que puede pagar cinco mil o más pesos por la anulación del vínculo, lo obtiene sin ninguna de las salvaguardias y las garantías para los hijos que consulta cualquiera ley de divorcio bien meditada." 23

"Quienes propiciamos el voto femenino amplio, no intentamos, en modo alguno, el gobierno de las mujeres ni un matriarcado como parecen temerlo algunos escritores. En absoluto. La democracia es cooperación y no subyugamiento. No todos los hombres tienen aptitudes para las ideas abstractas, ni vocación para la lucha política. Así acontece con las mujeres. La ciencia moderna ha demostrado que no existen diferencias psíquicas fundamentales entre ambos; sí una inmensa variedad de tipos en unos y en otras." ${ }^{24}$

“He aquí cómo el feminismo, y solamente con la mira de hallar un remedio a sus cuitas, hemos tenido que entrar en las 
más grandes cuestiones de la vida nacional. Es que no se divisa solución adecuada a los problemas feministas si no se les considera una parte de las interrogantes mundiales de esta época de atemorizante porvenir." 25

\section{Gilda Luongo en relación a Amanda Labarca:}

"Longeva, Amanda Labarca tuvo la fortuna de participar activamente entre tránsitos culturales complejos y heterogéneos (1886-1975). De esta manera supo de los avatares que la modernidad, en Chile y en América Latina, proporcionó a las mujeres que intentaron insertarse en este tránsito aun cuando ésta fuera una inserción subordinada; atisbó los desvelos experimentados en el devenir sujeto femenino resistente al mandato y calce genérico-sexual. En su escritura es posible detectar un movimiento pendular tensionado tanto por su adhesión militante y por la creencia en el proyecto feminista emancipatorio, utopía (im)posible, así como por la duda inevitable, la incertidumbre respecto del buen término de aquel proyecto. Sus estrategias discursivas y sus intentos de situarse como sujeto paritario en el campo cultural, dominantemente masculino, nos hablan de aquellas tretas de débil (Ludmer, 1985: 47-54) impulsadas y generadas para provocar la aceptación de la decibilidad de la 'automoderación' de sujetos femeninas intelectuales en las décadas del 20 al 50 (Muraro, 1995). Sus intereses interdisciplinarios la llevaron a escribir sobre feminismo, educación y crítica literaria, así como textos de ficción (novela corta y cuentos). La construcción de esta subjetividad en el marco de las experiencias de la modernidad se encuentran entretejidas en su decibilidad ensayística. La mayoría de las veces sus huellas se nos muestran claramente desde un pensamiento razonado que pretende la lucidez y la coherencia, como ocurre por ejemplo en la mayor parte del texto Feminismo contemporáneo (Labarca, 1947). Sin embargo, en otras textualidades, también se pueden rastrear -y desde este lugar hemos intervenido el (re)corte de sus textos- aquellos guiños silenciosos y casi secretos en los cuales están inscritos la contradicción, el atisbo de imposibilidad del proyecto, la desconfianza y el péndulo entre la posibilidad lanzada hacia el futuro y el presente que escamotea la certeza. Este tono también pulsa en algunos de los 
artículos que arman el entramado complejo de ¿A dónde va la mujer? (Labarca, 1934). Por otra parte, me interesa el (des)encuentro de los tonos discursivos que iluminan la construcción de la subjetividad en aquellos textos escritos para ser publicados y los de esa otra construcción hecha en los escritos íntimos, que escenifican las agonías existenciales y anticipan la necesaria y deseosa proximidad de la muerte. Otras urgencias escriturales y políticas dan lugar a las estrategias discursivas tomadas del melodrama y dirigidas a un público lector masivo tales como 'La maltratada' y 'Hogar, dulce hogar'; así como aquellas que quieren el razonamiento y la lucidez de la retórica más tradicional para abordar temas problemáticos para la época, tal como es la del divorcio." ${ }^{26}$

"Inserta de manera decididamente política en el contexto de Chile de la primera mitad del siglo, Labarca desea formar parte de lo nuevo sin desechar lo tradicional, se instala en el tono de la época, en ese desplazamiento que inevitablemente implica vuelco, revuelo, desorden, desplazamiento y emergencia: militante del Partido Radical, académica de la Universidad de Chile que tuvo a su cargo la labor de Extensión Universitaria en 1907, en la que impulsó lo que llamó Conferencias Populares que convocaban a sindicatos obreros y organizaciones culturales; fue la primera mujer en ser nombrada académica en la misma universidad y por último fue funcionaria de las Naciones Unidas. Los avatares en su acción y pensamiento se encuentran conectados con cierta intensidad de transformación y cambio en la segunda modernidad latinoamericana. Los espacios urbanos sociales, económicos y geográficos en los primeros años de desarrollo en nuestro continente implicaban la necesaria disposición hacia el vértigo de lo que está en el lugar de lo móvil y or lo tanto incierto. El desplazamiento constante de la disposición urbana del territorio citadino abría ventanas y puertas de escenas y escenarios no imaginados hasta entonces. Pasos y traspasos de todo tipo, coexistencia de sujetos y de proyectos políticos y culturales dan a los años en que Labarca trabaja, piensa y desea, una densidad que no puede sino traducirse en el entramado complejo y contradictorio que permea a esta sujeto productora de cultura. En este sentido es que me interesa considerar la figura del viaje como una estrategia discursiva develadora de las conexiones entre acción, pensamiento y afectaciones de la subjetividad de esta sujeto, que se anclan en el proyecto modernizador del feminismo que 
la autora desea promover, como un modo otro de producción cultural, social y político; así como un modo distinto de devenir ser humano conectado tanto a cierta racionalidad del progreso como a la tensión de ésta en cruce con cierta espiritualidad imaginada. La escritura de Labarca puede ser leída en este sentido como un entramado móvil, fluido, que implica lucha y búsqueda en la invención de posibilidades así como de estrategias y no sólo como una serie de escritos de carácter pedagógico, docilizadores

Y por ello carentes de problematizaciones o complejidades más profundas."

(....)

Su carrera profesional en educación se cruzaba con la construcción del relato feminista en nuestro entorno. La mayor parte de esta última reflexión la encontramos en los textos Feminismo contemporáneo y ¿A dónde va la mujer? La interrogante de ese último título insta a pensar que Labarca parte de un desplazamiento iniciado, de movimientos implícitos, de un descentramiento, a la manera de lo que ocurre en los viajes. Pensamos en el inicio de itinerarios que las mujeres han emprendido en la época. La pregunta implica que aquella movilidad debiera tener un recorrido, pero éste no está claro ni es cierto en el contexto de la década del 30. Lo obvio es que el lugar que la mujer ocupaba se ha desplazado, el (des)orden del lugar designado implica cierta migrancia. El viaje ha comenzado y en éste se atisban otros conflictos, escenas y escenarios: las salitreras y las mujeres trabajadoras, la instalación de las mujeres en la industria manufactuera, las escritoras en sus tertulias, viajes y lugares de encuentros con mujeres: círculos, clubes, centros. Todas aquellas dejaban de estar como antes y comenzaban a habitar este país de distinta manera: sujetos productoras, visibles en el espacio público. La complejidad de esta migrancia está inscrita en la indagación de Labarca." ${ }^{27}$

\section{Isabel Morel ${ }^{28}$}

“Actualmente el feminismo de verdad es gentil y admirable. Se posesiona de los defectos sociales y trata de remediarlos. Gentes hay que creen encontrar el feminismo en las exageraciones sociales, más o menos 'snobs': una muchacha que fuma, bebe, y dice palabras gruesas. Otra que se marcha de excursión, llevando 
llaves de puerta de calle para regresar a las cuatro de la mañana... Son estas las modalidades de una educación malsana, pero en ningún caso feminismo." ${ }^{29}$

\section{Elena Caffarena ${ }^{30}$}

"He dado preferencia al movimiento sufragista inglés tanto porque cronológicamente es el primero que aparece, como porque en esta etapa del feminismo están contenidas sus características más permanentes que dieron origen al movimiento femenino histórico de la época contemporánea".

(...) "el feminismo es un fenómeno social...no se origina accidentalmente. Tiene sus fundamentos en la realidad misma, emerge de los acontecimientos y tiene características y leyes propias." 31

"Cuando las feministas hablamos del principio de igualdad, no es que pretendamos ser física y biológicamente iguales a los hombres, sino es que esperamos iguales oportunidades ante la vida...Las protecciones se pagan siempre caras, sea que se otorguen a individuos o países...Toda protección tiene una contrapartida de sumisión. En la administración pública las mujeres hacen el papel de cenicientas. Sólo en casos rarísimos pasan del grado 8. Romper esta valla es una de las reivindicaciones más urgentes de la mujer funcionaria...Una ley de Jubilación Preferencial para la mujer dará argumento para que esta situación se mantenga...se dirá que siendo la carrera de la mujer más corta, es explicable y justo que no llegue a los más altos cargos." 32

"Me he aplicado el calificativo de feminista porque lo soy. No figuro entre las que Marta Vergara -feminista bastante olvidada- califica de "feministas vergonzantes", mujeres que lograron un título universitario, tuvieron o tienen altos cargos en la administración, la política, la vida social y creen que eso es sólo fruto de su talento y esfuerzo, olvidándose que si alcanzaron esas posiciones es porque muchas mujeres de aquí y del mundo, les abrieron el camino arrastrando mil dificultades y hasta persecuciones." 33 
"Las fuerzas tradicionales buscan por todos los medios sustraer el máximo de mujeres a una posición de combatividad. Los que están en el poder tratan de engañarnos con los llamados a la dignidad femenina y virtudes hogareñas. Son las mismas armas que en el siglo pasado se esgrimieron para denigrar, desfigurar y escupir a las valerosas inglesas que conquistaron para las mujeres del mundo los primeros escalones de su liberación." ${ }^{34}$

(Refiriéndose a Luis Emilio Recabarren): “...fue un feminista entusiasta. Su aporte al desarrollo del movimiento feminista es valiosísimo. Su nombre no puede ser olvidado sin cometer una injusticia por quien pretenda escribir la historia del feminismo chileno."

"Hay reivindicaciones fundamentales en las que ella debe estar al lado de sus hijos, su compañero de trabajo, de vida y por el otro, el de las específicas que derivan de su calidad de mujer, plano en el que puede estar en pugna muchas veces con sus hijos y sus propios compañeros." 35

\section{Olga Poblete escribe sobre Elena Caffarena:}

"Con suma modestia cuenta Elena:

También estuve presente en la fundación del Movimiento ProEmancipación de la Mujer Chilena MEMCH, 11 de mayo de 1935, del que fui Secretaria General por cinco años.

Esta mujer valiente, múltiple, contestataria, fue en realidad 'la' fundadora. Como en toda iniciativa, lo importante no fue sólo el primer impulso, sino la porfía por mantenerse fiel a los principios y tener el valor de seguir creciendo. Conocía claramente la carencia de derechos y oportunidades de las chilenas. Esta convicción animaba a otras jóvenes mujeres para quienes la vida no sólo era faena aislada, individual, sino parte de una complejidad colectiva de cuyas alegrías y pesares nadie escapaba. En los años veinte y treinta ocurrían en todo el orbe tremendas conmociones políticas, catástrofes económicas y confrontaciones ideológicas. Una encrucijada histórica que hacía aún más notoria la discriminación de la mujer. Chile era un país que había vivido ya las primeras etapas de su industrialización: tenía a su 
haber las luchas de un proletariado emergente, había conocido la prosperidad y caía al pozo de la "gran depresión" económica de los treinta, vivía los fermentos ideológicos de la revolución bolchevique de 1917 y más tarde las secuelas del fascismo y el nazismo que arrastrarían a la humanidad a la mayor catástrofe de su historia. Muchas de ellas protagonizaron atrevidas acciones para su tiempo en la FECH de los años veinte. De ahí el tono firme y desafiante que tienen los primeros escritos del $\mathrm{MEMCH}$ : sus Estatutos, sus peticiones, los conminatorios volantes de las campañas contra la carestía de la vida, el analfabetismo, los conventillos, el alcohol

El grupo compartía con Elena la intención de crear una entidad femenina nueva. Las "fundadoras": periodistas, abogadas, profesoras, algunas funcionarias de reparticiones públicas, coincidían en estimar la inutilidad de refugiarse en la crítica y el descontento personal y rechazaban los prejuicios que las discriminaban. Querían "ser y hacer", pero todas juntas, en pluralidad de condición social, política, cultural. Se les ocurrió MEMCH como vía para desatar energías, capacidades ignoradas y reprimidas. Fue así como un caudal de fuerza anónima y "tejiendo rebeldías" -expresión tan justa medio siglo después, de nuestra inolvidable Julieta Kirkwood, prematuramente desparecida- las fundadoras asumieron la tarea de convocar a otras mujeres a través del país.

En 1939, El MEMCH preparó la Exposición “La Mujer en la Vida Nacional", un proyecto de gran envergadura realizado con la colaboración de maestras, artistas, escritoras, obreras, madres de familia, muchachas y muchachos estudiantes.

En ese hormigueo de mujeres ocurrió mi primer encuentro con Elena Caffarena. Hasta entonces sólo me interesaba mi trabajo profesional, y aunque era profesora de Historia y también de Educación Cívica, prácticamente no había aterrizado en la compleja realidad socio-política de mi propio país. En justicia puedo asegurar que el MEMCH fue mi verdadera escuela de civismo. A partir de ese existencial encuentro me comprometí para siempre con la 'emancipación de la mujer'." 36 
1 Rosario Orrego (1834-1879). Novelista, periodista y académica.

2 Orrego, Rosario. Sus mejores poemas, artículos y su novela corta "Teresa". Grez Silva, Isaac (Biografía y selección). "El lujo y la moda". Santiago: Nascimento, 1931, 62-67. En: http: / / www.memoriachilena.cl

3 Rosa Rubí. La Tromba, Santiago de Chile, 06 de marzo de 1898, Nª1, páginas 6 y 7. Citado en: Palomera, Adriana y Alejandra Pinto (Compiladoras). Mujeres y prensa anarquista en Chile (1897-1931), Santiago: Ediciones Espíritu Libertario, Colección Histórica Osvaldo Bayer, 2006, 23.

4 Teresa Claramunt (1862-1931). Quizás la primera revolucionaria española del siglo XIX. Anarcosindicalista. Una de las militantes fundamentales del movimiento libertario español. En 1903 publicó: La mujer, consideraciones sobre su estado ante las prerrogativas del hombre.

5 Claramunt, Teresa. La Agitación. Santiago de Chile, noviembre de 1901, Na3, página 1. Citado en: Palomera, Adriana y Alejandra Pinto (Compiladoras). Mujeres y prensa anarquista en Chile (1897-1931), Santiago: Ediciones Espíritu Libertario, Colección Histórica Osvaldo Bayer, 2006, 25 y 26.

6 Laura. “¿Hasta cuando?”, en Germinal, Santiago de Chile, 20 de julio de 1904, N33, página 2. Citado en: Palomera, Adriana y Alejandra Pinto (Compiladoras). Mujeres y prensa anarquista en Chile (1897-1931). Santiago: Ediciones Espíritu Libertario, Colección Histórica Osvaldo Bayer, 2006, 35 y 36.

7 Palomera, Adriana y Alejandra Pinto (Compiladoras). “Introducción". En: Mujeres y prensa anarquista en Chile (1897-1931). Santiago: Ediciones Espíritu Libertario, Colección Histórica Osvaldo Bayer, 2006, 17-18.

8 Carmela Jeria. Obrera tipógrafo, fundadora del primer periódico feminista obrero en Chile, La Alborada en 1905, fue junto a otras mujeres una luchadora frente a los derechos de los trabajadores y las mujeres.

9 Jeria, Carmela. “Nuestra situación”. En: La Alborada. Valparaíso, Santiago: Impr. El Deber, 1905-1907. 42 nos., año II, n² 29, (27 enero 1907), 1. En: http / / www.memoriachilena.cl

10 Martina Barros (1850-1941) Escritora, tradujo el libro The subjection of women de Stuart Mill, desatando múltiples reacciones tanto en los sectores conservadores como liberales de la sociedad de su época. Por su origen familiar, tuvo una formación intelectual poco común a las mujeres de su tiempo. Es considerada una precursora del feminismo en Chile, preocupada especialmente de la igualdad de las mujeres y del derecho a sufragio.

11 Martina Barros, Prólogo a La esclavitud de la mujer (Estudio crítico por John Stuart Mill), publicado en la Revista Santiago en 1872, escrito para la presentación de la traducción que ella hiciera de la obra de Stuart Mill, The Subjection of Women (1869). Tomado de: Alejandra Castillo, Editorial Palinodia, Colección Archivo Feminista, Santiago, 2009, 59-61.

12 Alejandra Castillo, "Estudios preliminar. Las aporías de un feminismo liberal: Martina Barros traductora de Stuart Mill", en Martina Barros, Prólogo a La esclavitud de la mujer (Estudio crítico por John Stuart Mill). Edición, notas y estudio preliminar de Alejandra Castillo, Editorial Palinodia, Colección Archivo Feminista, Santiago, 2009, 35-36.

13 Ernestina Pérez. Nació el año 1868 en Valparaíso. En 1887, se recibió de médico de la Facultad de Medicina de la Universidad de Chile a los 21 
años. Apoyada por el Estado, continuó formándose en Europa, en particular en Alemania país donde no se aceptaban mujeres en las universidades, restricción que la obligó a asistir a clases separada de los hombres por un biombo. Ernestina Pérez manifestó, tempranamente, una preocupación por los problemas de la llamada "higiene social", liderando la lucha contra males como el alcoholismo, la tuberculosis y el cólera, entre otros. Por último, es llamativa su participación en organizaciones femeninas tales como el Círculo de Lectura, el Club de Señoras, la Cruz Roja Chilena, y la Asociación de Mujeres Universitarias de Chile, de la cual fue su primera presidenta. En dicha Asociación compartió con profesionales tan notables como Amanda Labarca y Elena Caffarena. Ernestina Pérez murió a los 86 años de edad.

14 Pérez, Ernestina. Conferencia sobre el Alcoholismo, dada en el Club de Señoras por la Doctora Ernestina Pérez. Santiago de Chile: Imprenta Universitaria, 1920, 23.

15 Gabriela Mistral (1889-1957). Fue una destacada poeta, diplomática y pedagoga chilena. Es una de las principales figuras de la literatura chilena y latinoamericana, es la primera persona latinoamericana en ganar el Premio Nobel de Literatura, el cual recibió en 1945.

16 Mistral, Gabriela. "La imagen de cristo en la escuela", artículo, en Gabriela y México, Pedro Pablo Zegers, Ril Editores, 2007, 213-219.

17 Gabriela Mistral, La instrucción de la mujer, 1906, cita en Sonia Montecino (Comp.), Mujeres Chilenas. Fragmentos de una historia, Santiago, Editorial Catalonia, 2008, 97.

18 Raquel Olea. Como traje de fiesta. Loca razón en la poesía de Gabriela Mistral. Santiago: Editorial USACH. Colección Humanidades, 2009, 59-75.

19 Ortega, Eliana. “Amada amante”. En: Raquel Olea y Soledad Fariña (eds.). Una palabra cómplice. Encuentro con Gabriela Mistral. Santiago: La Morada/ Editorial Cuarto Propio, Isis Internacional, 1990, 1997, 136-138.

20 Amanda Labarca (1886 - 1975). Fue profesora de Estado en Castellano, además estudió en Universidad de Columbia en Estados Unidos, y en la Universidad de La Sorbona, para especializarse en educación escolar. Fue una destacada feminista y luchadora por los derechos de la mujer, trabajó junto a Celinda Reyes y logró la aprobación de la Ley maza. Fue una de las fundadoras del Comité Nacional Pro derechos de la Mujer junto a Elena Caffarena en 1933. En 1946 fue nombrada embajadora antes las Naciones Unidas y jefa de sección de Estatus de la mujer. Fue también crítica literaria y escritora, preocupándose especialmente por el rol de la mujer en la sociedad. Dirigió el periódico del Círculo de Lectura, Acción Femenina, que tuvo destacada participación en la lucha por la obtención del voto femenino, gracias a ello, en 1944, es electa presidenta de la Federación Chilena de Instituciones Femeninas. Se dedicó a dar clases y charlas por toda América.

21 Labarca, Amanda. "Una mujer enjuicia al tiempo": discurso de incorporación pronunciado por la Sra. Amanda Labarca en la sesión solemne del 7 de diciembre de 1970. Discurso de recepción del presidente de la Academia D. Juvenal Hernández Jaque. Santiago: Andrés Bello, 1971, 29.

22 Labarca, Amanda. ¿A dónde va la mujer? Santiago de Chile: Editorial Extra, 1934, 23-24-25-34-54.

23 Labarca, Amanda. ¿A dónde va la mujer?, "En defensa del divorcio". Santiago de Chile: Editorial Extra, 1934, 204. 
24 Labarca, Amanda. Feminismo contemporáneo. Santiago: Editorial Zig-Zag, 1947, 144. Citado por Raquel Olea en "El poder de decir". En: Sonia Montecino (ed.). Mujeres chilenas. Fragmentos de una historia. Santiago: Editorial Catalonia, 2008, 292.

25 Labarca, Amanda. ¿A dónde va la mujer? Santiago de Chile: Editorial Extra, 1934, 39. Citado por Gilda Luongo en el capítulo "La escritura de viaje de Amanda Labarca". En: Alicia Salomone et al. Modernidad en otro tono. Escritura de mujeres latinoamericanas: 1920-1950. Santiago: Editorial Cuarto Propio, 2004, 77.

26 Luongo, Gilda. "Contrapunto para cuatro voces: emergencias privadas / urgencias públicas en la escritura de mujeres". Revista Scielo. 2005.

27 Labarca, Amanda. ¿A dónde va la mujer? Santiago de Chile: Editorial Extra, 1934, 39. Citado por Gilda Luongo en el capítulo "La escritura de viaje de Amanda Labarca". En: Alicia Salomone et al. Modernidad en otro tono. Escritura de mujeres latinoamericanas: 1920-1950. Santiago: Editorial Cuarto Propio, 2004, 69-73.

28 Isabel Morel. Escritora y activista chilena es autora de la publicación "Charlas Femeninas", trabajó por el derecho al sufragio de las mujeres, y fue parte de MEMCH.

29 Morel, Isabel. Feminismo. En: Revista "Charlas Femeninas". Viña del Mar, Chile: Impr. El Stock, 1930, 183.

30 Elena Caffarena (1903-2003). Estudió Derecho en la Universidad de Chile, participando activamente de la Federación de Estudiantes. En 1935 funda el Movimiento de Emancipación de las Mujeres de Chile (MEMCH), organización que congregó a importantes feministas. Su principal lucha fue lograr la ampliación de los derechos políticos de las mujeres, especialmente el voto. Durante la dictadura militar trabajó por la defensa de los derechos humanos a través del Comité de Defensa de los Derechos del Pueblo (CODEPU).

31 Expresiones de Elena Caffarena, memchista y jurista, citadas por Olga Poblete, historiadora y memchista. Citas tomadas de "Un Capítulo en la Historia del Feminismo. Las sufragistas inglesas". Ediciones MEMCH. 1952. Olga Poblete. Una mujer, Elena Caffarena. Santiago: Editorial Cuarto Propio, 1993,70 .

32 Carta al Director de "Democracia”, agosto 1952. En: Una mujer, Elena Caffarena. Santiago: Editorial Cuarto Propio, 1993, 80.

33 Seminario sobre los derechos de la mujer. Instituto para el Nuevo Chile. Santiago, 1986. En: Una mujer, Elena Caffarena. Santiago: Editorial Cuarto Propio, 1993, 92.

34 Archivo MEMCH. 1952. En: Una mujer, Elena Caffarena. Santiago: Editorial Cuarto Propio, 1993, 104.

35 "Luis Emilio Recabarren, Feminista". Artículo de Elena Caffarena para el diario El Siglo, diciembre 1953. En: Una mujer, Elena Caffarena. Santiago: Editorial Cuarto Propio, 1993, 96.

36 Poblete, Olga. Una mujer, Elena Caffarena. Santiago: Editorial Cuarto Propio/La Morada, 1993, 41-46. 